\title{
Graphene Ink Modified Glassy Carbon Electrode as electrochemical sensor for Galantamine Determination
}

\author{
Haobin Shi ${ }^{1}$, Yuhong Zheng ${ }^{2}$ Mengyao $\mathrm{Wu}^{1}$ and $\mathrm{Li} \mathrm{Fu}{ }^{1, *}$ \\ ${ }^{1}$ College of Materials and Environmental Engineering, Hangzhou Dianzi University, Hangzhou, \\ 310018, P.R. China \\ ${ }^{2}$ Institute of Botany, Jiangsu Province and Chinese Academy of Sciences, Nanjing Botanical Garden, \\ Mem. Sun Yat-Sen, Nanjing 210014, P.R. China. \\ *E-mail: fuli@hdu.edu.cn
}

doi: $10.20964 / 2019.02 .56$

Received: 15 September 2018 / Accepted: 6 November 2018 / Published: 5 January 2019

\begin{abstract}
In this study, commercial graphene ink has been used as a cost-effective modifier for glassy carbon electrode (GCE) surface modification. The excellent conductivity and defects triggered electrocatalytic property of the graphene ink showed a superior performance in electrochemical sensing. Galantamine, an alkaloid isolated from Lycoris, has been selected as an analyte for evaluating the graphene inkmodified GCE. A clear signal enhancement with reduction of overpotential was observed using a GCE after a simple graphene ink surface modification process. A linear detection range from $20 \mu \mathrm{M}$ to 180 $\mu \mathrm{M}$ of galantamine was recorded on the proposed electrode with a low limit of detection of $4.1 \mu \mathrm{M}$.
\end{abstract}

Keywords: Graphene ink; Galantamine; Surface modification; Electrochemical sensor; Glassy carbon electrode

\section{FULL TEXT}

(C) 2019 The Authors. Published by ESG (www.electrochemsci.org). This article is an open access article distributed under the terms and conditions of the Creative Commons Attribution license (http://creativecommons.org/licenses/by/4.0/). 